\title{
Evidence for immunoreactive relaxin in boar seminal vesicles using combined light and electron microscope immunocytochemistry
}

\author{
T. Kohsaka ${ }^{1}$, H. Takahara ${ }^{2}$, H. Sasada ${ }^{3}$, T. Kawarasaki ${ }^{4}$, K. Bamba ${ }^{5}$, \\ J. Masaki ${ }^{3}$ and $\mathbf{S}$. Tagami
}

${ }^{1}$ Laboratory of Animal Reproduction and Feeding, and ${ }^{2}$ Laboratory of Biochemistry, Faculty of Agriculture, Ibaraki University, Ibaraki 300-03, Japan; ${ }^{3}$ Laboratory of Animal Reproduction, Faculty of Agriculture, Tohoku University, Sendai 981, Japan; ${ }^{4}$ Division of Biotechnology, Shizuoka Pig and Poultry Research Center, Shizuoka 439, Japan; and ${ }^{5}$ Laboratory of Animal Reproduction, Faculty of Agriculture, Shizuoka University, Shizuoka 420, Japan

\begin{abstract}
Summary. Light-microscope immunocytochemistry using the peroxidase-antiperoxidase technique and a polyclonal rabbit antiserum raised against purified porcine relaxin showed that cytoplasmic immunostaining for relaxin could be visualized in the epithelial cells of the seminal vesicle. No relaxin immunoreactivity was seen in the testis, epididymis, ductus deferens, prostate or bulbo-urethral gland. A ten times higher concentration of porcine relaxin antiserum was necessary to achieve immunostaining in the seminal vesicle comparable to that in the corpora lutea of pregnant sows.

Ultrastructural examination showed that the epithelial cells of the boar seminal vesicle resembled typical protein-secreting cells with prominent rough endoplasmic reticulum and well-developed Golgi apparatus. The most striking feature of these cells was the accumulation of granules with a limiting membrane, which ranged from 200 to $600 \mathrm{~nm}$ in diameter and contained flocculent material of moderate electron density. Electron-microscope immunocytochemistry using the protein A-gold technique and relaxin antiserum demonstrated that the granules were the only intracellular organelles that showed immunoreactivity for relaxin.

These results indicate that a relaxin-like substance is present in boar seminal vesicles and that the subcellular site of its localization is the granules, suggesting that the seminal vesicle produces and stores a relaxin-like substance, but that it is present at much lower concentrations than in the corpora lutea of pregnant sows.
\end{abstract}

Keywords: relaxin; seminal vesicle; immunocytochemistry; boar

\section{Introduction}

Relaxin is a peptide of about $6 \mathrm{kDa}$ produced by the corpus luteum and is considered to be a hormone of pregnancy with an active role in various reproductive processes, including the widening of the birth canal and the suppression of uterine motility (Porter, 1979). Nevertheless, the existence of a similar peptide in the males of some mammalian species has been suggested since a small amount of relaxin bioactivity was found in an extract from rooster testes (Steinetz et al., 1959). In men, relaxin immunoreactivity has been detected in the plasma (Bryant, 1972) and the seminal plasma (Loumaye et al., 1980; Essig et al., 1982a; De Cooman et al., 1983; Brenner et al., 1987), and it has been suggested that the accessory sex glands act as the storage sites for a relaxinlike substance (Yki-Jarvinen et al., 1983). Relaxin immunoreactivity is also found in boar plasma 
(Bryant, 1972). The first report on the tissue localization of this relaxin-like substance in boars was by Dubois \& Dacheux (1978) on the testis. They observed immunoreactive relaxin mainly in the interstitial cells, with only weak activity in the Sertoli cells. Subsequently, Arakaki et al. (1980) could not confirm this finding. More recently, immunoreactive relaxin has again been reported in boar seminal plasma, but its tissue localization was not established (Juang et al., 1990).

The present study incorporated light and electron microscope immunocytochemistry to determine whether immunoreactive relaxin was present in the reproductive organs of boars and to determine its subcellular localization. We used corpora lutea of pregnant sows as a control tissue for the localization of relaxin.

\section{Materials and Methods}

\section{Tissue collection and preparation for light microscopy}

Five mature Landrace boars and two pregnant Landrace sows were used. The organs collected were the testis, epididymis (caput, corpus and cauda), ductus deferens, seminal vesicle, prostate, bulbo-urethral gland and the midtrimester corpus luteum. The animals were killed at a local slaughterhouse and the tissues were quickly removed. The central part of each organ was removed and cut into small pieces, which were fixed for $12 \mathrm{~h}$ at $4^{\circ} \mathrm{C}$ in Bouin's solution, embedded in paraplast and then cut into sections of $5 \mu \mathrm{m}$. The sections were mounted on gelatin-coated glass slides.

\section{Light-microscope immunocytochemistry}

Deparaffinized sections were immunostained by the peroxidase-antiperoxidase method (Sternberger, 1979). Before immunostaining, the sections were treated for $20 \mathrm{~min}$ with $3 \%$ hydrogen peroxide dissolved in pure ethanol to block endogenous peroxidase activity and then incubated for $20 \mathrm{~min}$ with $2 \%$ normal goat serum to saturate nonspecific binding sites for immunoglobulin $\mathrm{G}$ ( $\operatorname{IgG})$. The sections were next incubated in order with (i) various dilutions (1:50-l:10000) of antirelaxin serum for $12 \mathrm{~h}$ at $4^{\circ} \mathrm{C}$, (ii) goat anti-rabbit IgG (Zymed Laboratories, San Francisco, CA, USA) diluted at 1:40 for $30 \mathrm{~min}$ at room temperature and (iii) peroxidase-antiperoxidase rabbit serum (Organon Teknika, West Chester, PA, USA) diluted at 1:60 for $45 \mathrm{~min}$ at room temperature. After each step, the sections were washed three times for $5 \mathrm{~min}$ in $0.01 \mathrm{~mol}$ phosphate-buffered saline (PBS) $\mathrm{I}^{-1}, \mathrm{pH} \mathrm{7.2}$. Visualization of peroxidase activity was performed using 3-3'diaminobenzidin (Nakarai Chemicals, Tokyo, Japan) as the substrate. To test the specificity of the immunostaining, we incubated some sections with normal rabbit serum or with antirelaxin serum absorbed for $5 \mathrm{~h}$ at $4^{\circ} \mathrm{C}$ with a purified porcine relaxin standard (NIH-RXN-Pl, $50-200 \mu \mathrm{g} \mathrm{ml}^{-1}$ ), as a substitute for the antiserum. After incubation, all the sections were dehydrated in a graded ethanol series, mounted and examined with an Olympus interference-contrast photomicroscope. The intensity of immunostaining was expressed as negative $(-)$, weak $(+)$, moderate $(++)$ or strong $(+(++(++)$.

\section{Tissue collection and preparation for electron microscopy}

Three mature Landrace boars were used. The animals were killed at a slaughterhouse and the seminal vesicles were removed quickly. To avoid the cellular artifacts due to the diffusion of secretions, we immersed the whole tissue in $4 \%$ paraformaldehyde containing $0.3 \%$ glutaraldehyde in PBS for $2 \mathrm{~h}$ at $4{ }^{\circ} \mathrm{C}$ and then cut into slices of $5 \mathrm{~mm}$ with a razor blade. These tissue slices were then immersed in the fixative for a further $2 \mathbf{h}$. After overnight washing in PBS, the blocks were fixed for $1 \mathrm{~h}$ at $4^{\circ} \mathrm{C}$ in $1 \%$ osmium tetroxide in PBS, dehydrated in an ethanol series and embedded in epoxy resin. In addition, the corpora lutea obtained from one Landrace sow during late pregnancy were used as a positive control after processing under the same experimental conditions. Ultrathin sections were cut and then placed on 150-mesh uncoated nickel grids. To observe the ultrastructure of the seminal vesicle and corpus luteum, some sections of each tissue were stained with uranyl acetate and lead citrate. Quantitative evaluation of the cytoplasmic granules was performed for the sections of seminal vesicle and corpus luteum. Electron micrographs of cells of each tissue taken at a magnification of $\times 2000$ were enlarged to $\times 6000$ and the numbers of granules in each cell were counted manually. Measurements were made only on cells in which the nucleus was present. The number of granules per cell was determined in 36 cells for seminal vesicle and in 22 cells for corpus luteum.

\section{Electron-microscope immunocytochemistry}

Ultrathin sections were immunolabelled by the protein A-gold technique (Roth et al., 1978). Before immunolabelling, the sections of the seminal vesicle and the corpus luteum were incubated for $1 \mathrm{~h}$ at room temperature in a saturated aqueous solution of sodium metaperiodate (Bendayan \& Zollinger, 1983), to allow the labelling of cellular antigenic sites in osmicated tissues, and then washed for $30 \mathrm{~min}$ in PBS containing $1 \%$ bovine serum albumin (BSAPBS). Then the sections of seminal vesicles and corpora lutea were incubated for $12 \mathrm{~h}$ at $4^{\circ} \mathrm{C}$ with porcine relaxin antiserum diluted at 1:500 in BSA-PBS. After washing in BSA-PBS, the sections were incubated for 30 min at room temperature in protein A-gold (Janssen Biotech, Olen, Belgium) diluted at 1:50 in PBS, followed by washing in PBS 
and distilled water. All incubations were carried out on drops placed on parafilm in a moist chamber. After drying in air, the sections were contrasted with uranyl acetate and then examined with a JEM-100B electron microscope at $80 \mathrm{kV}$. The specificity of the immunolabelling was confirmed by incubation with normal rabbit serum, or with porcine relaxin antiserum preabsorbed with a purified porcine relaxin standard. To preabsorb the antiserum, $50 \mu \mathrm{g}$ and $100 \mu \mathrm{g}$ porcine relaxin were added to $500 \mu \mathrm{l}$ of antiserum diluted at 1:5000 and 1:500, respectively, and allowed to incubate for $5 \mathrm{~h}$ at $4^{\circ} \mathrm{C}$. Quantitative evaluation of the gold particles labelling organelles was performed after the treatment of seminal vesicle sections with unabsorbed antiserum and relaxin-absorbed antiserum. Randomly selected electron micrographs taken at a magnification of $\times 20000$ were enlarged to $\times 50000$. The number of gold particles labelling each subcellular compartment was counted manually and the labelling intensity was expressed as mean ( \pm SEM) number of gold particles per labelled organelle. The results obtained were statistically analysed using Student's $t$ test and $P<0.0$ l was considered to indicate a significant difference.

\section{Porcine relaxin antiserum}

The antirelaxin serum used was the R19 antiserum raised in rabbits by Larkin et al. (1977) against purified relaxin prepared from the ovaries of pregnant sows. This antiserum inhibits the action of porcine relaxin in vitro (Larkin et al., 1979) and gives a single line of identity when tested in Ouchterlony plate assay against purified porcine relaxin standard (Pardo et al., 1980).

\section{Results}

Using the peroxidase-antiperoxidase technique and an antiserum to purified porcine relaxin, immunoreactive relaxin was detected in boar reproductive organs (Table 1). Immunoreactive relaxin was found in the seminal vesicles of all the animals tested. The brown reaction products indicating relaxin immunoreactivity could be visualized in the cytoplasm of the seminal vesicle epithelial cells (Fig. 1). Optimum immunostaining was obtained when the porcine relaxin antiserum was used at a dilution of 1:500. Higher dilutions of the antiserum reduced the staining; lower dilutions caused a weak and nonspecific immunoreaction. Under optimum conditions, the intensity of the immunostaining of the seminal vesicles still varied somewhat between animals (Table 1). The same conditions did not reveal any staining in the testis, epididymis, ductus deferens, prostate or bulbo-urethral gland (Figs 2-5). The immunostaining observed in the seminal vesicle was effectively blocked when the antiserum was preabsorbed with purified porcine relaxin (data not shown).

Table 1. Distribution and intensity of relaxin immunoreactivity in reproductive organs of boars

\begin{tabular}{|c|c|c|c|c|c|c|c|c|}
\hline & Testis & caput & $\begin{array}{c}\text { Epididym } \\
\text { corpus }\end{array}$ & cauda & $\begin{array}{l}\text { Ductus } \\
\text { deferens }\end{array}$ & $\begin{array}{l}\text { Seminal } \\
\text { vesicle }\end{array}$ & $\begin{array}{l}\text { Prostate } \\
\text { gland }\end{array}$ & $\begin{array}{l}\text { Bulbo-urethral } \\
\text { gland }\end{array}$ \\
\hline $\begin{array}{l}\text { Intensity of } \\
\text { staining } \\
\text { Number of tissue } \\
\text { samples studied } \\
\text { from five boars }\end{array}$ & - & - & - & - & - & ++ to ++ & - & - \\
\hline
\end{tabular}

$(-)$ negative, $(++)$ moderate, $(+++)$ strong intensity of immunostaining.

When the corpora lutea of pregnant sows were used to determine the relaxin antiserum concentration necessary for optimal immunostaining intensity in comparison with that of the seminal vesicle, the optimal staining intensity of the corpus luteum was effective at a 1:5000 dilution (Fig. 6a). At the same antiserum dilution, staining of the seminal vesicle was still evident, but very weak (Fig. 6b).

The ultrastructural features of the epithelial cells of the seminal vesicle suggested that they were protein-secreting cells (Fig. 7a), since rough endoplasmic reticulum and a well-developed Golgi apparatus were evident. A striking feature of these epithelial cells was the presence of granules surrounded by a limiting membrane. The granules were round, about $200600 \mathrm{~nm}$ in diameter, and contained flocculent material (Fig. 7). A population of these granules was located near the luminal 

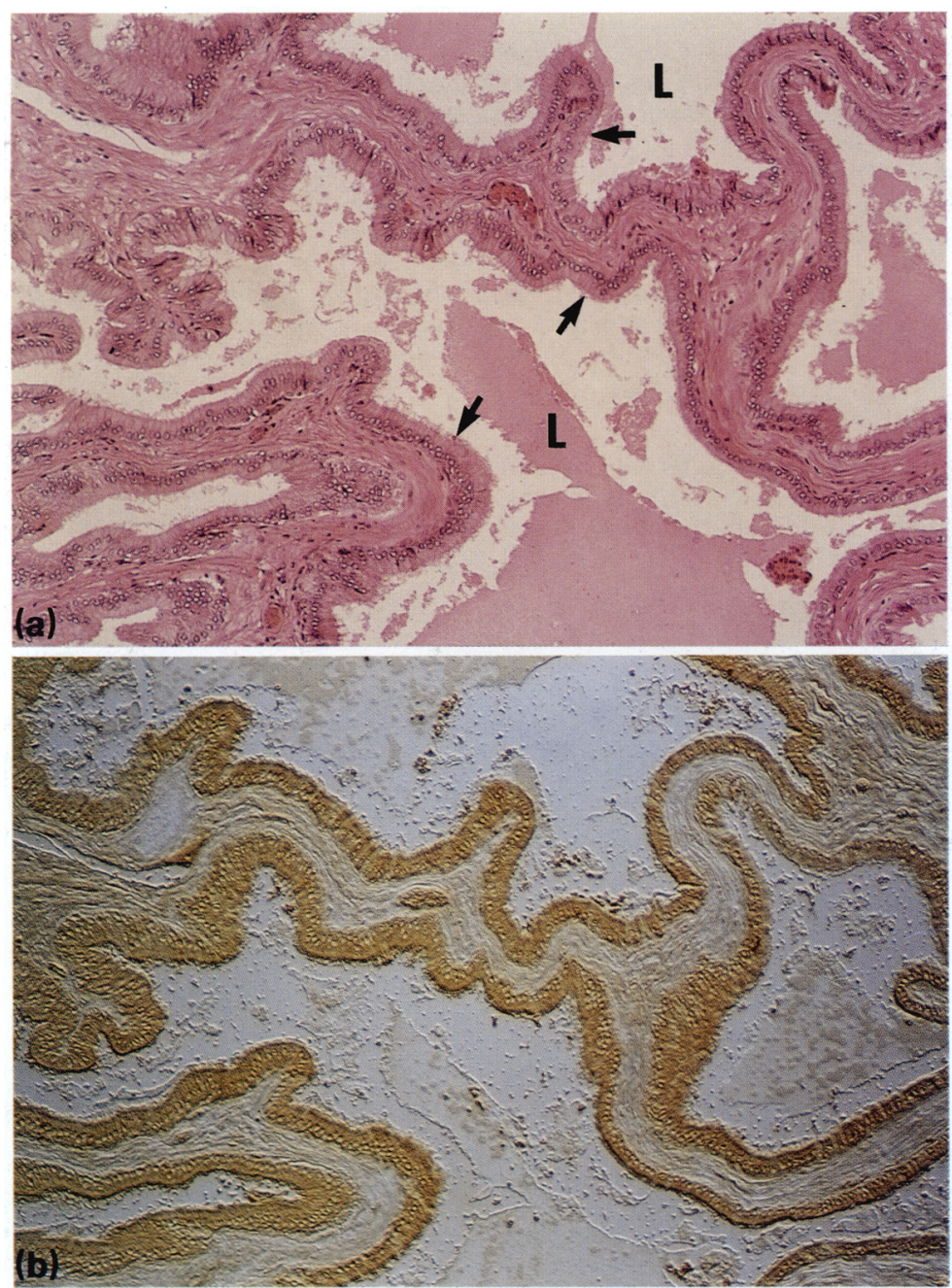

Fig. 1. Light micrographs $(\times 75)$ of sections of boar seminal vesicle: (a) stained with haematoxylin and eosin; the seminal vesicle is composed of intricate, branching and anastomosing folds that give rise to apparently isolated luminal cavities (L), which account for the honeycomb appearance of the tissue and are lined by a single layer of cuboidal epithelium (arrows); and (b) stained by the peroxidase-antiperoxidase technique with antiporcine relaxin diluted at 1:500; the brown reaction products that indicate relaxin immunoreactivity are prominent in the epithelial cells.

surfaces of the cell (Fig. 7b). The electron density of granules in the seminal vesicle was moderate in comparison with the granules in the pregnant sow corpus luteum. The granules in the corpus luteum were round, ranged from 200 to $300 \mathrm{~nm}$ in diameter, and contained homogeneous electrondense material (Fig. 8). The mean number of granules per cell was 20 times greater in the corpus luteum than in the seminal vesicle (Table 2).

To examine the subcellular localization sites of the immunoreactive relaxin in the epithelium of the seminal vesicle, the ultrathin sections were incubated with a 1:500 dilution of the relaxin antiserum and protein A-gold. Gold particles indicating immunoreactivity for relaxin were found in most, but not all, of the granules within the cytoplasm of the epithelial cells (Fig. 9a), although the gold labelling was sparse. The immunolabelling of these organelles was blocked by incubation with either normal rabbit serum or porcine relaxin antiserum preabsorbed with purified porcine relaxin 

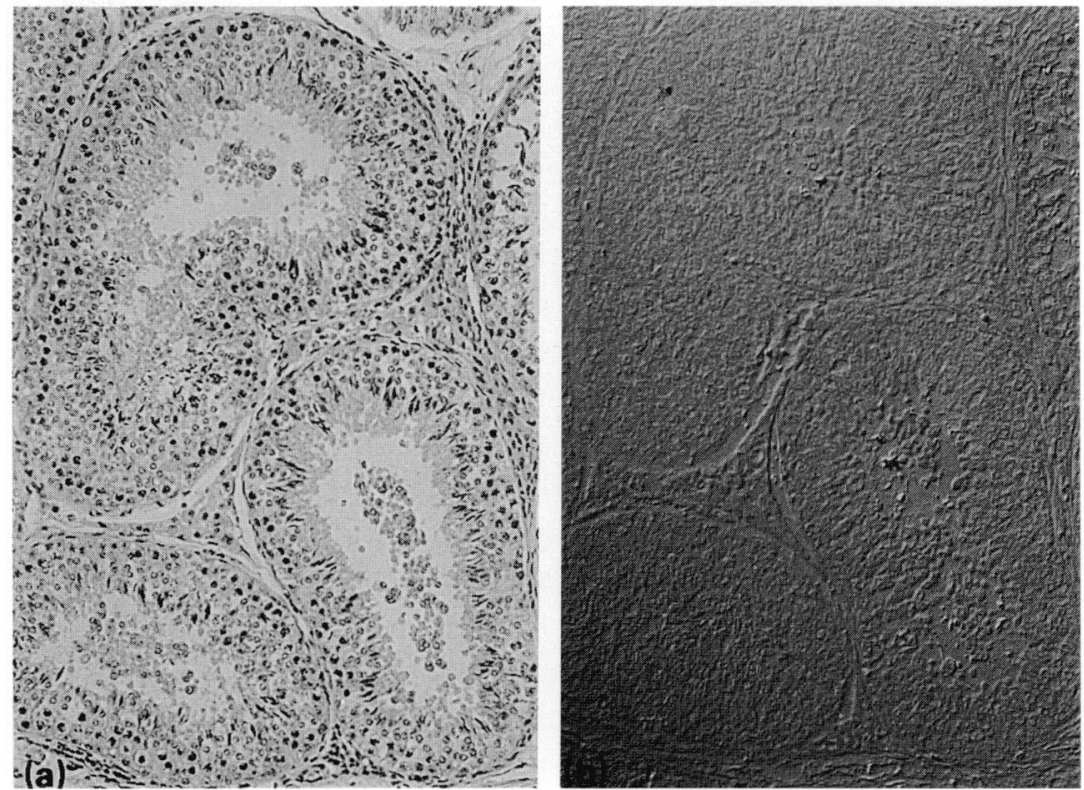

Fig. 2. Light micrographs $(\times 100)$ of sections of boar testis stained with $(a)$ haematoxylin and eosin and (b) by the peroxidase-antiperoxidase technique with antiporcine rclaxin diluted at 1:500; no immunostaining is noted.
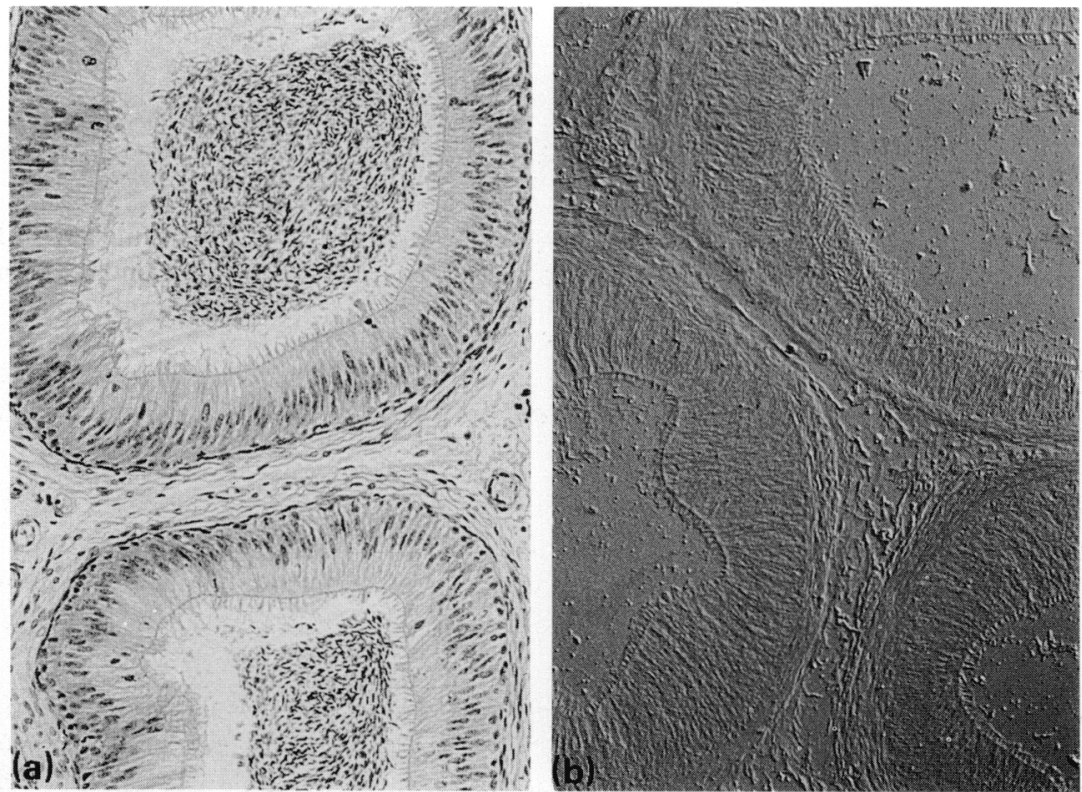

Fig. 3. Light micrographs $(\times 100)$ of sections of boar corpus epididymis stained with (a) haematoxylin and eosin and (b) by the peroxidase-antiperoxidase technique with antiporcine relaxin diluted at 1:500; no immunostaining is noted. 

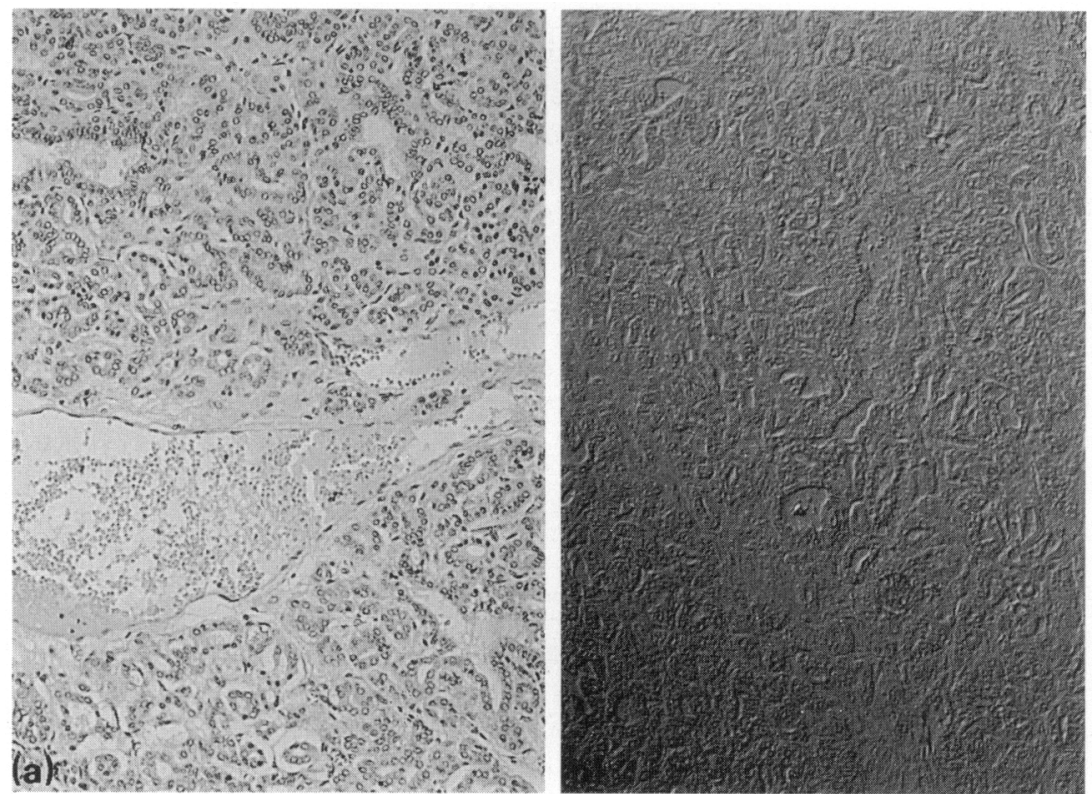

Fig. 4. Light micrographs $(\times 100)$ of sections of boar prostate gland stained with (a) haematoxylin and eosin and (b) by the peroxidase-antiperoxidase technique with antiporcine relaxin diluted at 1:500; no immunostaining is noted.
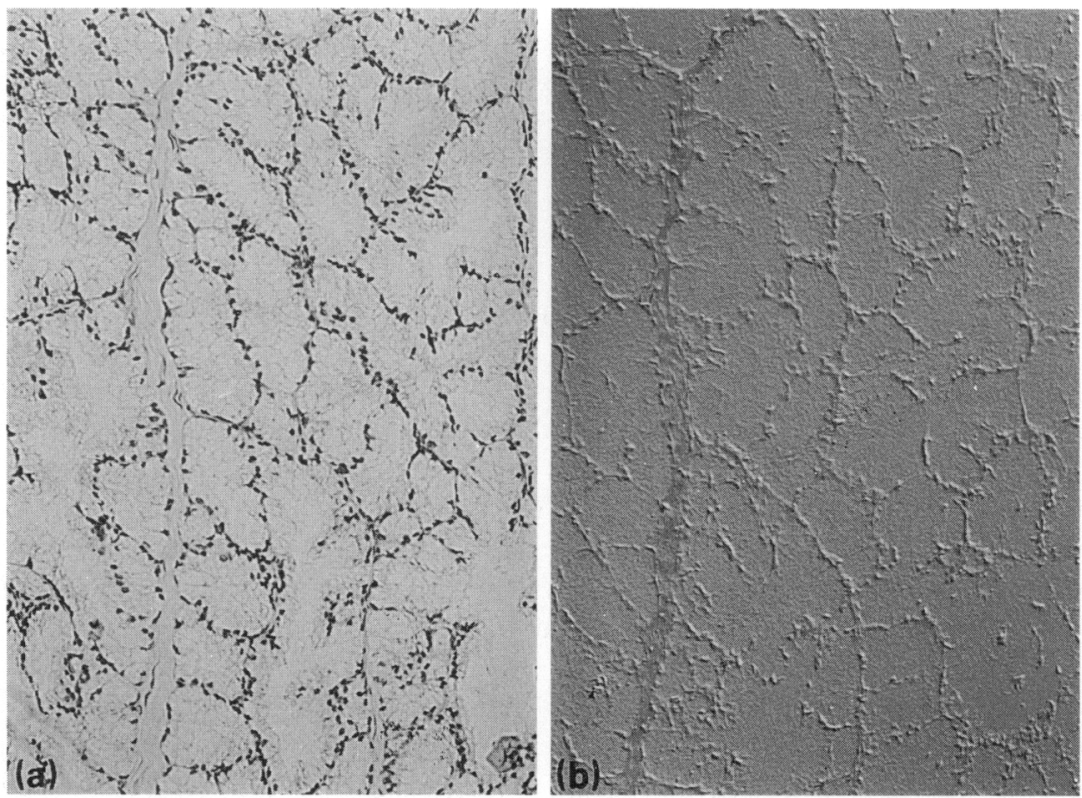

Fig. 5. Light micrographs $(\times 100)$ of sections of boar bulbo-urethral gland stained with (a) haematoxylin and eosin and (b) by the peroxidase-antiperoxidase technique with antiporcine relaxin diluted at 1:500; no immunostaining is noted. 
(Fig. 9b). One advantage of using the protein A-gold technique for ultrastructural immunocytochemistry is that the labelling density can be easily quantified by counting the number of particles. The gold labelling of the granules in sections treated with unabsorbed relaxin antiserum was significantly higher $(P<0.01)$ than in sections treated with relaxin-absorbed antiserum (Table 3$)$. This confirmed that the gold labelling was specific. In contrast, when ultrathin sections of corpus luteum were incubated with a 1:5000 dilution of the antiserum and protein A-gold, the dense cores of most of the granules were labelled with gold particles (Fig. 10).

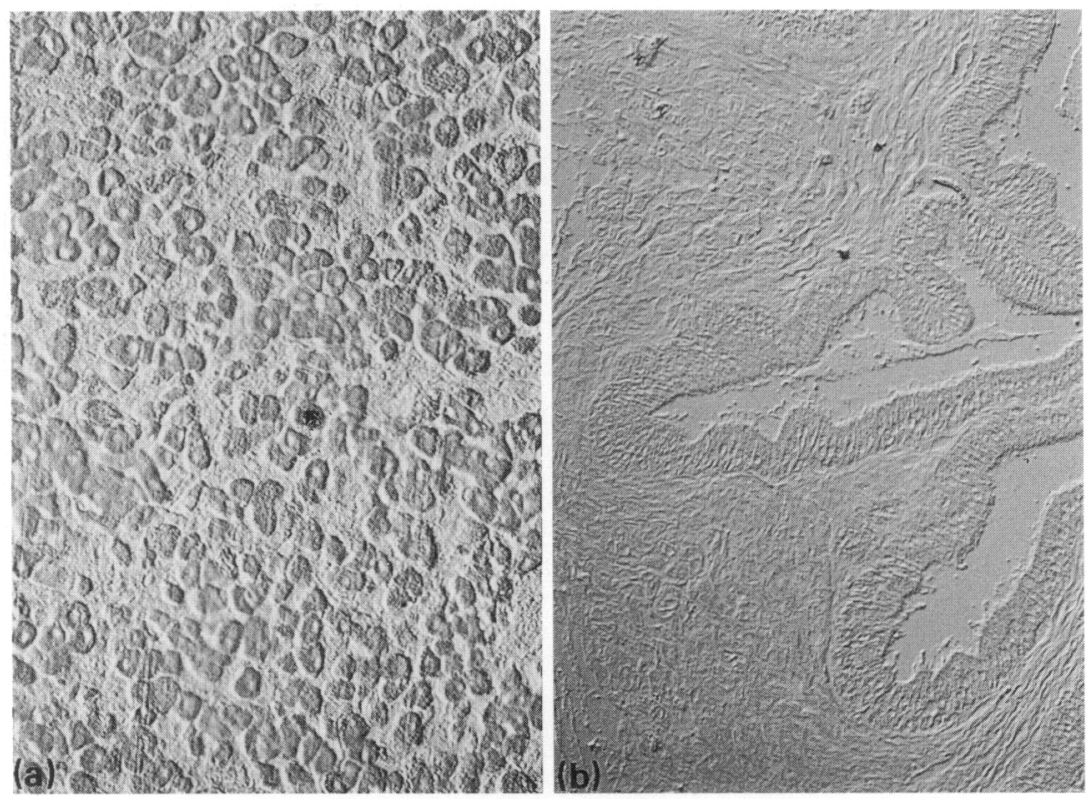

Fig. 6. Light micrographs $(\times 100)$ of sections of (a) the corpus luteum of a pregnant sow and (b) boar seminal vesicle, both stained by the peroxidase-antiperoxidase technique with antiporcine relaxin diluted at 1:5000. The immunostaining intensity in (a) is similar to that in the seminal vesicle shown in Fig. $1 \mathrm{~b}$; that in (b) is very weak.

\section{Discussion}

Although Bryant (1972) was successful in detecting plasma relaxin immunoreactivity in boars and rams by a radioimmunoassay for crude porcine relaxin, this finding has not been confirmed by subsequent investigators, probably because the relaxin preparation used by Bryant (1972) contained approximately $85 \%$ nonrelaxin peptides (Schwabe et al., 1978). However, Juang et al. (1990) have recently detected relaxin immunoactivity in boar seminal plasma using a radioimmunoassay for purified porcine relaxin, although the cellular source of this substance was not established. This paper presents the first evidence for cellular and subcellular localization of immunoreactive relaxin in the seminal vesicles of boars.

We investigated the distribution of immunoreactive relaxin in the reproductive organs of mature boars by using a sensitive, peroxidase-antiperoxidase, immunohistochemical technique and an antiserum against purified porcine relaxin. Our results clearly showed that relaxin immunostaining was confined to the epithelium of the seminal vesicle. No immunostaining was found in other reproductive tissues, including the testis. The staining of the seminal vesicle was sufficiently blocked by incubation of the antiserum with purified porcine relaxin. These results suggest that the seminal 


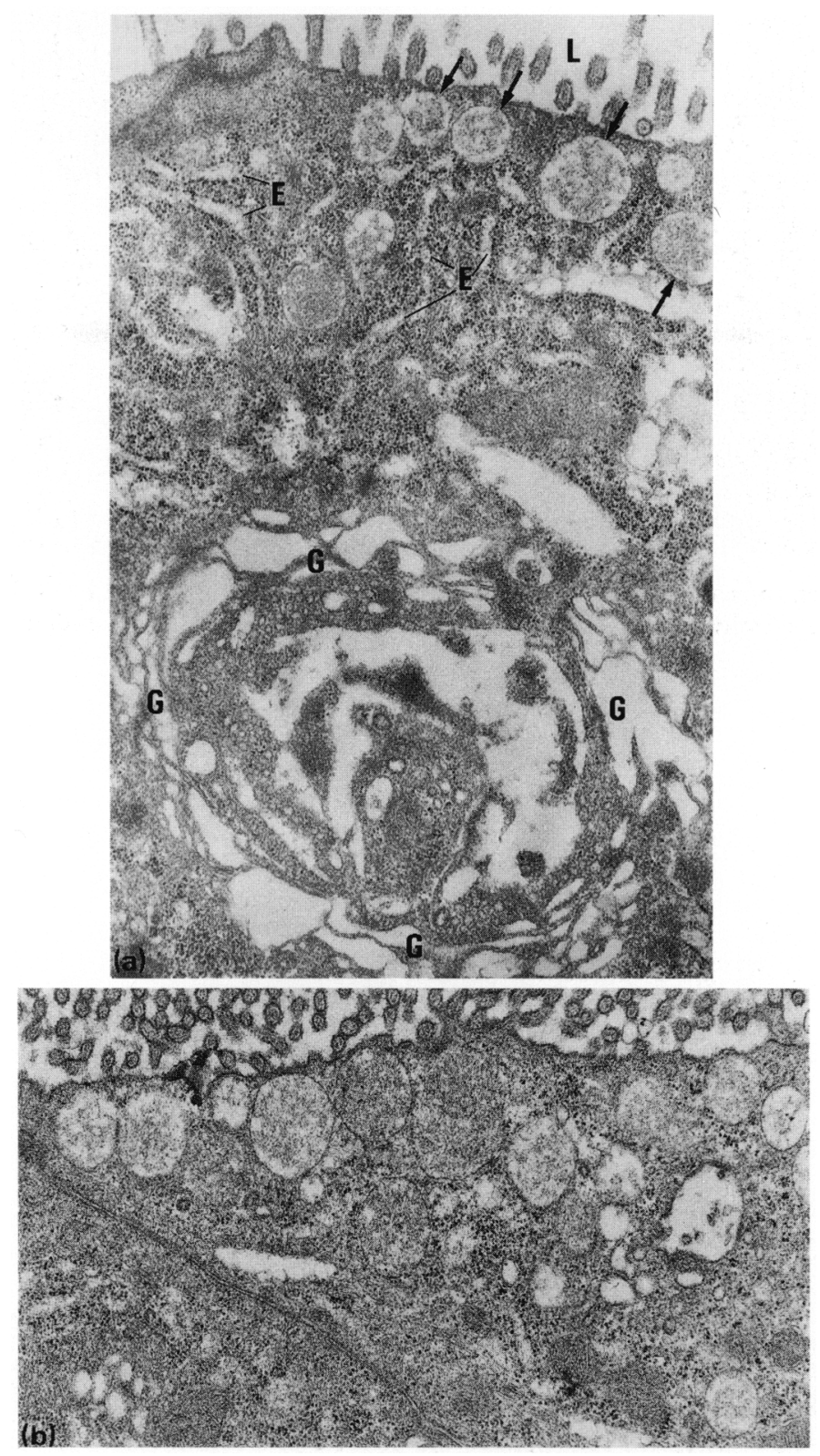

Fig. 7. Electron micrographs $(\times 12650)$ of boar seminal vesicle epithelial cells. Granules (arrows) containing flocculent moderately electron-dense material are surrounded by a limiting membrane in (a) and are located near the luminal border of the cell in (b); rough endoplasmic reticulum (E) and well-developed Golgi apparatus (G) can also be seen in (a); (L) lumen.

vesicle is the storage site for a relaxin-like substance in this animal. In an earlier study, Dubois \& Dacheux (1978) reported the presence of immunoreactive relaxin in the interstitial and Sertoli cells of boar testis using an indirect immunofluorescence procedure and an antiserum to crude porcine relaxin. However, Arakaki et al. (1980) could not confirm this when repeating the study using an antiserum to purified porcine relaxin. Our findings support the work of Arakaki et al. (1980) and extend it by showing the presence of relaxin in an accessory organ, the seminal vesicle. 


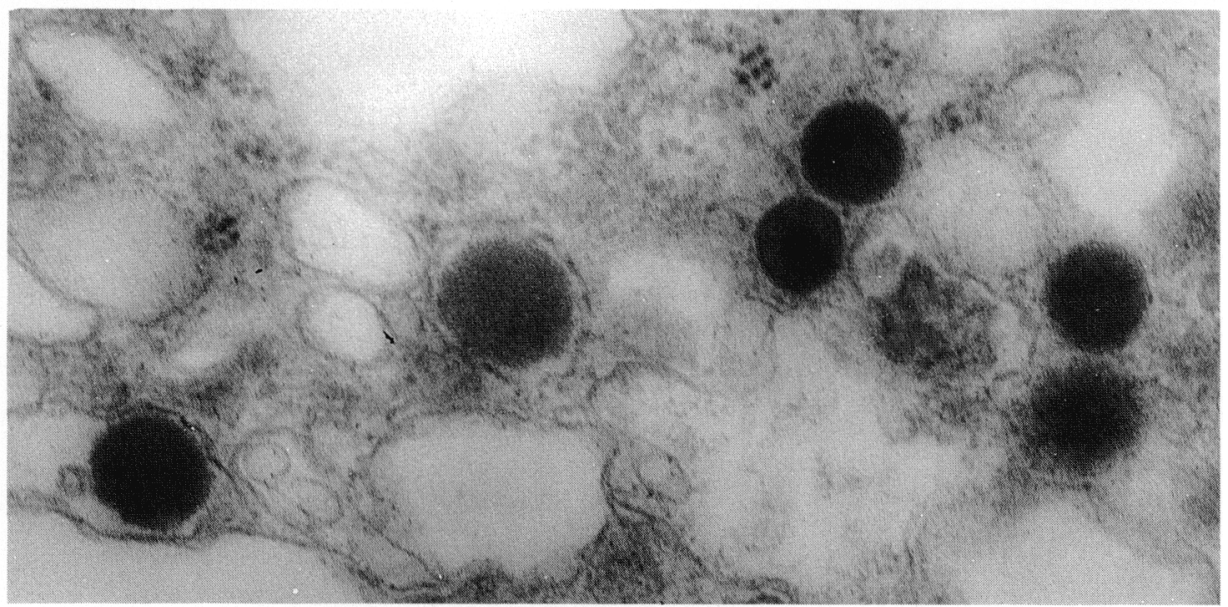

Fig. 8. Electron micrograph $(\times 54000)$ of a luteal cell of a pregnant sow. Note the granules surrounded by a limiting membrane and containing homogeneous electron-dense material.

Table 2. Mean ( \pm SEM) number of granules per cell in the seminal vesicle of boar and corpus luteum of pig

\begin{tabular}{lcc}
\hline Tissues & $\begin{array}{c}\text { Number } \\
\text { of } \\
\text { cells* }\end{array}$ & $\begin{array}{c}\text { Number } \\
\text { of granules } \\
\text { per cell }\end{array}$ \\
\hline Seminal vesicle & 36 & $18 \cdot 6 \pm 1 \cdot 5$ \\
Corpus luteum & 22 & $373 \cdot 0 \pm 26 \cdot 6$ \\
\hline
\end{tabular}

*Cells of each tissue were examined at a magnification of $\times 2000$; measurements were made only on cells with a nucleus.
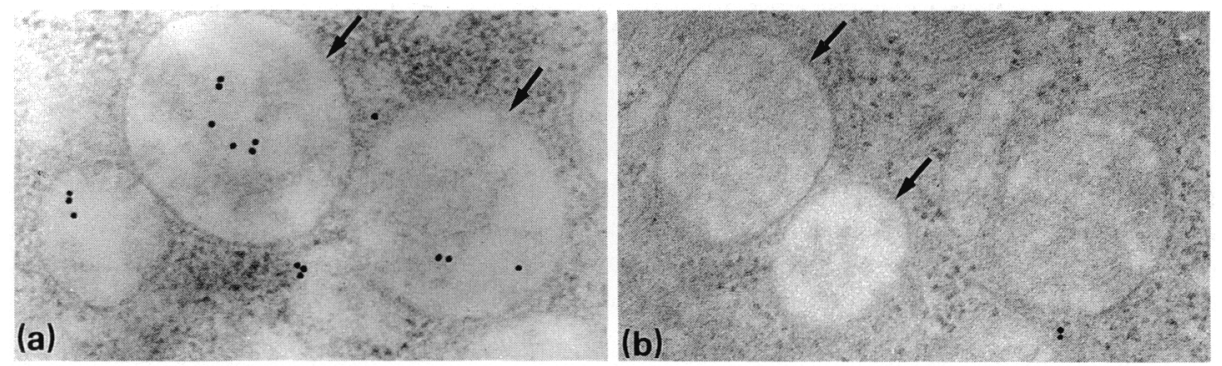

Fig. 9. Immunoelectron micrographs $(\times 38400)$ of granules in a boar seminal vesicle epithelial cell: sections incubated with (a) antiporcine relaxin diluted at 1:500, followed by protein Agold. The gold particles indicating relaxin immunoreactivity have mainly labelled the cores of the granules (arrows); and (b) preabsorbed antiserum $(0.5 \mathrm{ml}$ of antiporcine relaxin diluted at 1:500 and preabsorbed with $100 \mu \mathrm{g}$ of the porcine relaxin standard), followed by protein A-gold. Note the absence of gold labelling in the granules (arrows). 
Table 3. Mean ( \pm SEM) number of gold particles per granule in seminal vesicle epithelial cells of boars after treatment with unabsorbed relaxin antiserum and relaxin-absorbed antiserum

\begin{tabular}{|c|c|c|c|}
\hline Treatment & $\begin{array}{l}\text { Number } \\
\text { of } \\
\text { cells* }\end{array}$ & $\begin{array}{c}\text { Number } \\
\text { of } \\
\text { granules }\end{array}$ & $\begin{array}{l}\text { Number } \\
\text { gold particles } \\
\text { per granule }\end{array}$ \\
\hline Unabsorbed antirelaxin & 16 & 68 & $3.25 \pm 0.37^{\mathrm{a}}$ \\
\hline Absorbed antirelaxin & 12 & 67 & $0.55 \pm 0 \cdot 13^{b}$ \\
\hline
\end{tabular}

*Cells containing granules were examined at a magnification of $\times 20000$.

Means with different superscripts are significantly different $(P<0.01)$.

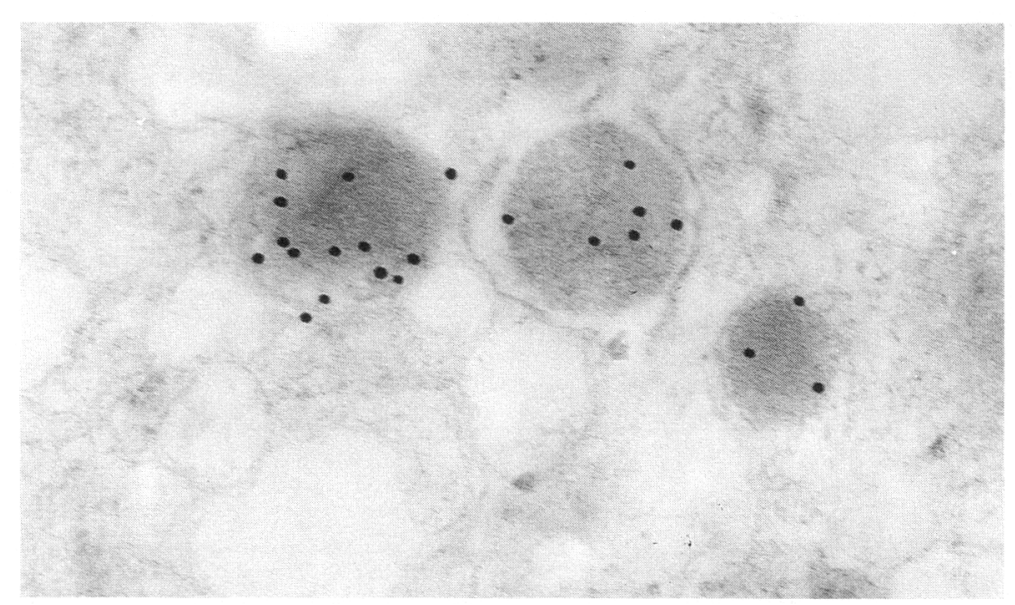

Fig. 10. Immunoelectron micrograph $(\times 64000)$ of granules in a luteal cell of a pregnant sow. The section was incubated with antiporcine relaxin diluted at 1:5000, followed by protein A-gold. The gold particles have labelled the dense cores of the granules.

Although light microscopy suggested that the seminal vesicle was the storage site for immunoreactive relaxin in boars, it was not clear whether this relaxin was produced there. Accordingly, we performed an electron-microscope immunocytochemical analysis. It is generally accepted that most of the cells producing protein hormones have a characteristic ultrastructure featuring three cellular compartments (Parade, 1975), i.e. rough endoplasmic reticulum, Golgi apparatus and membrane-limited granules. If immunoreactive relaxin is produced by boar seminal vesicles, it is thought to be stored in the membrane-limited granules in a similar manner to storage of relaxin in luteal cells of pigs (Kendall et al., 1978; Fields \& Fields, 1985) and rats (Anderson \& Sherwood, 1984; Fields, 1984), in guinea-pig endometrial gland cells (Pardo et al., 1984), and in golden hamster placentas (Johns \& Renegar, 1990). The present study showed that typical epithelial cells of boar seminal vesicles had similar ultrastructural features to cells producing protein hormones. Rough endoplasmic reticulum and well-developed Golgi apparatus were evident. The most striking features of the cells were accumulations of granules surrounded by a limiting membrane. When ultrathin sections of seminal vesicles were incubated with the relaxin antiserum and protein A-gold, the granules were the only organelles that showed immunoreactivity for relaxin. Thus, it seems reasonable to draw the conclusion that immunoreactive relaxin is packed into the granules via the Golgi apparatus after synthesis by the rough endoplasmic reticulum, in accordance with the general pathway described by Parade (1975). Our data support the contention that the seminal vesicle is the 
secretory organ for immunoreactive relaxin in boars. Studies on relaxin gene expression have been performed in extracts of corpora lutea in sows (Bagnell et al., 1990a) and in humans (Ivell et al., 1989) and of ovarian follicles in sows (Bagnell et al., 1990b), using DNA-RNA hybridization analysis. The detection of relaxin mRNA is a better way of assessing the site of synthesis than electron-microscope immunocytochemical analysis. To substantiate our finding, it is therefore necessary to determine whether relaxin mRNA can be detected in boar seminal vesicles using the DNA-RNA hybridization technique.

The ultrastructural features of the granules containing immunoreactive relaxin in boar seminal vesicles differ from those of the granules in the corpus luteum of pigs (Kendall et al., 1978; Fields \& Fields, 1985) and rats (Anderson \& Sherwood, 1984; Fields, 1984). The granules of the seminal vesicle epithelium were larger in diameter and contained flocculent electron-moderate material, in contrast to the granules of pig and rat corpus luteum, which are smaller in diameter and contain homogeneous electron-dense material. The reason for these discrepancies in the size and electron density of the granules is unclear, but the presence of flocculent, electron-moderate material in the granules of the seminal vesicle was not an artifact, since the granules of the pig corpus luteum contained homogeneous electron-dense material after preparation of sections under the same experimental conditions.

At the light-microscope level, the relaxin antiserum concentration necessary for optimum immunostaining was ten times higher in boar seminal vesicles than in corpora lutea of pregnant sows. This may be because concentrations of the immunoreactive substance are low in the seminal vesicles. This suggestion is supported by the comparison of the number of granules in the corpus luteum and seminal vesicle at the electron-microscope level: the mean number of granules per cell was 20 times greater in the pig corpus luteum than in the boar seminal vesicle.

Recent immunohistochemical studies have indicated that relaxin immunoreactivity can be visualized in the glandular epithelium of the prostate and seminal vesicle in men (Yki-Jarvinen et al., 1983) and in the prostate gland of armadillos (Cameron et al., 1982); the latter group of investigators used the antirelaxin serum (R19) that we used in the present study. Thus, our findings add further evidence that a relaxin-like substance may be a component of male accessory sex glands.

Boar seminal vesicles are known to be a major source of seminal plasma (Mann, 1981). The presence of immunoreactive relaxin in the seminal vesicle indicates a new direction for research into porcine reproduction. Purified porcine relaxin has been reported to stimulate human sperm motility (Essig et al., 1982b; Colon et al., 1986). Hence, the immunoreactive relaxin found in boar seminal vesicles may have a physiological effect on ejaculated spermatozoa. Juang et al. (1990) have pointed out that immunoreactive relaxin detected in boar semen by radioimmunoassay for porcine relaxin was positively correlated with boar sperm motility. This substance may have other effects on sperm transport or fertilization.

A combined light-microscope and electron-microscope immunocytochemical study clearly showed that the epithelial cells of boar seminal vesicles are the cellular source of immunoreactive relaxin and that cytoplasmic granules represent the subcellular sites of relaxin localization, suggesting that boar seminal vesicles produce and store immunoreactive relaxin.

The authors wish to thank L. H. Larkin, Department of Anatomy, University of Florida College of Medicine, for the kind supply of porcine relaxin antiserum R19; and S. Raiti, National Hormone and Pituitary Program, National Institutes of Health in USA, for kindly providing the purified porcine relaxin standard (NIH-RXN-P1). This work was presented in part at the 11 th International Congress on Animal Reproduction and Artificial Insemination, Ireland, 1988.

\section{References}

Anderson, M.B. \& Sherwood, O.D. (1984) Ultrastructural localization of relaxin immunoreactivity in corpora lutea of pregnant rats. Endocrinology 144, $1124-1127$
Arakaki, R.F., Kleinfeld, R.G. \& Bryant-Greenwood, G.D. (1980) Immunofluorescence studies using antisera to crude and to purified porcine relaxin. Biology of Reproduction 23, 153-159. 
BagnelI, C.A., Tashima, L., Tsark, W., Ali, S.M. \& McMurtry, J.P. (1990a) Relaxin gene expression in the sow corpus luteum during the cycle, pregnancy, and lactation. Endocrinology 126, 2514-2520.

Bagnell, C.A., Tsark, W., Tashima, L., Downey, B.R., Tsang, B.K. \& Ainsworth, L. (1990b) Relaxin gene expression in the porcine follicle during preovulatory development induced by gonadotrophins. Journal of Molecular Endocrinology 5, 211-219.

Bendayan, M. \& Zollinger, M. (1983) Ultrastructural localization of antigenic sites on osmium-fixed tissues applying the protein A-gold technique. Journal of Histochemistry and Cytochemistry 31, 101-109.

Brenner, S.H., Lesing, J.B., Schoenfeld, C., Goldsmith, L.T., Amelar, R.D., Dubin, L. \& Weiss, G. (1987) Human semen relaxin and its correlation with the parameters of semen analysis. Fertility and Sterility 47, $714-716$.

Bryant, G.D. (1972) The detection of relaxin in porcine, ovine and human plasma by radioimmunoassay. Endocrinology 91, 1113-1117.

Cameron, D.F., Corton, G.L. \& Larkin, L.H. (1982) Relaxin-like antigenicity in the armadillo prostate gland. Annals of the New York Academy of Sciences 380, 231-240.

Colon, J.M., Ginsburg, F., Lessing, J.B., Schoenfeld, C., Goldsmith, L.T., Amelar, R.D., Dubin, L. \& Weiss, G. (1986) The effect of relaxin and prostaglandin $E_{2}$ on the motility of human spermatozoa. Fertility and Sterility 46, 1133-1139.

De Cooman, S., Gilliaux, P.\& Thomas, K. (1983) Immunoreactive relaxin-like substance in human split ejaculates. Fertility and Sterility 39, 111-113.

Dubois, M.P. \& Dacheux, J.L. (1978) Relaxin, a male hormone? Immunocytological localization of a relaxin antigen in the boar testis. Cell and Tissue Research 187, 201-214.

Essig, M., Schoenfeld, C., D'Elette, R., Amelar, R.D., Dubin, L., Steinetz, B.G., O'Byrne, E.M. \& Weiss, G. (1982a) Relaxin in human seminal plasma. Annals of the New York Academy of Sciences 380, 39-45.

Essig, M., Schoenfeld, C.S., Amelar, R.D., Dubin, L. \& Weiss, G. (1982b) Stimulation of human sperm motility by relaxin. Fertility and Sterility 38, 339-343.

Fields, P.A. (1984) Intracellular localization of relaxin in membrane-bound granules in the pregnant rat luteal cell. Biology of Reproduction 30, 753-762.

Fields, P.A. \& Fields, M.J. (1985) Ultrastructural localization of relaxin in the corpus luteum of the nonpregnant, pseudopregnant, and pregnant pig. Biology of Reproduction 32, 1169-1179.

Ivell, R., Hunt, N., Khan-Dawood, F. \& Dawood, M.Y. (1989) Expression of the human relaxin gene in the corpus luteum of the menstrual cycle and in the prostate. Molecular and Cellular Endocrinology 66, $251-255$.

Johns, T.C. \& Renegar, R.H. (1990) Ultrastructural morphology and relaxin immunolocalization in giant trophoblast cells of the golden hamster placenta. American Journal of Anatomy 189, 167-178.
Juang, H.H., Musah, A.I., Schwabe, C. \& Anderson, L.L. (1990) Immunoreactive relaxin in boar seminal plasma and its correlation with sperm motility. Animal Reproduction Science 22, 47-53.

Kendall, J.Z., Plopper, C.G. \& Bryant-Greenwood, G.D. (1978) Ultrastructural immunoperoxidase demonstration of relaxin in corpora lutea from a pregnant sow. Biology of Reproduction 18, 94-98.

Larkin, L.H., Fields, P.A. \& Oliver, R.M. (1977) Production of antisera against electrophoretically separated relaxin and immunofluorescent localization of relaxin in porcine corpus luteum. Endocrinology 101, 679-685.

Larkin, L.H., Suarez-Quian, C.A. \& Fields, P.A. (1979) In vitro analyses of antisera to relaxin. Acta Endocrinologica 92, 568-576.

Loumaye, E., De Cooman, S. \& Thomas, K. (1980) Immunoreactive relaxin-like substance in human seminal plasma. Journal of Clinical Endocrinology and Metabolism 50, $1142-1143$.

Mann, T. (1981) Secretory function of the prostate, seminal vesicle, Cowper's gland and other accessory organs of reproduction. In Male Reproductive Function and Semen, pp. 171-268. Springer-Verlag, Berlin.

Parade, G. (1975) Intracellular aspects of process of protein synthesis. Science 189, 347-358.

Pardo, P., Larkin, L.H. \& Fields, P.A. (1980) Immunocytochemical localization of relaxin in endometrial glands of the pregnant guinea pig. Endocrinology 107, $2110-2112$.

Pardo, R.J., Larkin, L.H. \& Renegar, R.H. (1984) Immunoelectron microscopic localization of relaxin in endometrial gland cells of the pregnant guinea pig. Anatomical Record 209, 373-379.

Porter, D.G. (1979) Relaxin: old hormone, new prospect. In Oxford Reviews of Reproductive Biology, Vol. 1. pp. 1-57. Ed. C. A. Finn. Clarendon Press, Oxford.

Roth, J., Bendayan, M. \& Orci, L. (1978) Ultrastructural localization of intracellular antigens by use of protein A-gold complex. Journal of Histochemistry and Cytochemistry 26, 1074-1081.

Schwabe, C., Steinetz, B.G., Weiss, G., Segaloff, A., McDonald, J.K., O'Byrne, E.M., Hochmam, J., Carriere, B. \& Goldsmith, L. (1978) Relaxin. Recent Progress in Hormone Research 34, 123-211.

Steinetz, B.G., Beach, V.L. \& Kroc, R.L. (1959) The physiology of relaxin in laboratory animals. In Recent Progress in the Endocrinology of Reproduction, pp. 389-427. Ed. C. H. Lloyd. Academic Press, New York.

Sternberger, L.A. (1979) The unlabelled antibody peroxidase-antiperoxidase (PAP) method. In Immunocytochemistry, 2nd edn, pp. 104-169. John Wiley and Sons, New York.

Yki-Jarvinen, H., Wahlstrom, T. \& Seppala, M. (1983) Immunohistochemical demonstration of relaxin in the genital tract of men. Journal of Reproduction and Fertility 69, 693-695.

Received 25 March 1991 